\begin{tabular}{c} 
Volume and Issues Obtainable at Center for Sustainability Research and Consultancy \\
Journal of Business and Social Review in Emerging Economies \\
ISSN: 2519-089X (E): 2519-0326 \\
Volume 6: No. 2, June 2020 \\
JSRᄃ \\
Journal homepage: www.publishing.globalcsrc.org/jbsee \\
\hline
\end{tabular}

\title{
Cultivation Effects of Social Media on Cognitive, Social and Moral Skills of Adolescents in Pakistan
}

\author{
${ }^{1}$ Aemen Khalid, ${ }^{2}$ Taimoor ul Hassan, ${ }^{3}$ Ghulam Shabir \\ ${ }^{1}$ Phd Scholar, UCP, Assistant Professor ,Lahore Garrison University, Pakistan: \\ aemen.khalid@hotmail.com \\ ${ }^{2}$ Dean, Faculty of Media and Communication Studies, University of the Central Punjab, Lahore, \\ Pakistan: dr.taimoor@ucp.edu.pk \\ ${ }^{3}$ Professor, Faculty of Media and Communication Studies, University of the Central Punjab, Lahore, \\ Pakistan: ghulam.shabir@ucp.edu.pk
}

\begin{tabular}{l} 
ARTICLE DETAILS \\
\hline History \\
Revised format: May 2020 \\
Available Online: June 2020
\end{tabular}

Keywords

Facebook, Adolescents, Social

Skills, Cognitive Skills, Moral

Skills, Pakistan

JEL Classification:

L63, L69, J24

\section{ABSTRACT}

This research work aims to find out social, cognitive and moral effects of facebook on adolescents in Pakistan, because about 65\% of the country comprises on adolescents. The researcher applied quantitative research methods, while survey was conducted for the collection of data. Structured questionnaires were used for collection of data. Data was collected through purposive sampling method. Data was analyzed by Statistical Package for Social Sciences. The findings revealed that social media, particularly Facebook has cognitive, social and moral effects, which improve their skills to in-touch with relatives, peers and friends to improve social circle, cognitive effects to enhance creativity and mental level during the studies and moral effects where, they bear to respond the slang and abusive language as well as abusive comments on other posts related to their political and religious beliefs. This study also tests the cultivation theory with regard to social media and generated user categories according to their usage of facebook for future researchers. The results of the study justified the objectives and hypotheses of the study, where it has been recommended to parents, teachers and government to regulate the social media in the country to overcome the abuses.

Corresponding author's email address: aemen.khalid@ hotmail.com

Recommended citation: Khalid, A., Hassan, T. U. \& Shabir, G., (2020). Cultivation Effects of Social Media on Cognitive, Social and Moral Skills of Adolescents in Pakistan. Journal of Business and Social Review in Emerging Economies, 6(2), 419-436

DOI: $10.26710 /$ jbsee.v6i2.1146

\section{Introduction}

Adolescence is a time of life that is both exhilarating and daunting. It can be fraught with excitement and disappointment, self-confidence and insecurity, camaraderie and loneliness (Boyd, 2007). 
Communications media - whether pen and paper, phone calls, Facebook, or Twitter - can exacerbate or alleviate the peril to teenage life, or even do both at the same time. But today's social media have the potential to amplify age-old anxieties in ways that yesterday's communications media did not - by opening once-private exchanges for an entire school to see, adding photos and videos to words, allowing an entire community the chance to comment on what is seen or heard or said online, and by maintaining a permanent record of all those interactions (Rideout, 2012)

Large parts of Asia and Western countries are observing a generation of adolescent and young community members who have depleted their complete lives surrounded by Internet, games and mobile phones (Ito et al., 2008). Throughout the preceding decade, interactive media, consisting of games, social media and Internet applications, have turned out to be the tools for information and communication that are widely used by the so-called 'Netgeneration' (Tapscott, 1998).

Social media has positive impact on the cognitive and social skills of children and adolescents. Active participants of interactive media and computer users have positive impact on their verbal communication and cooperation skills and also show greater regard for rules of the game, with leadership qualities and greater patience for their turn to initiate communication (Foster, Erickson et al 1994). Investigation regarding the effects of media on adolescent's development is subject to interpretation. Historically, panic surrounds the introduction of new technologies, particularly in relation to children and youth (Quigley \& Blashki, 2003). Research conducted early in the social integration of new technologies is often 'ruled by the folklore of common cultural pessimism' (Boehnke et al, 2002, p. 193). Not surprisingly, television is related to various unwanted developmental outcomes, like aggression and obesity (Bushman \& Huesmann, 2001; Dennison et al, 2002; Gentile \& Walsh, 2002), but viewing educational television improves academic and cognitive skills in children (Anderson et al, 2000, 2001; Bickham et al, 2001; Naigles \& Mayeux, 2001). Video game playing is associated with social isolation and low self-esteem (Funk \& Buchman, 1996), but Roe \& Muijs (1998) found that children who played video games for more than two hours a day read more than children who did not engage in such heavy use of video games. Healy (1998) claimed that 'more and more college-age students are addicted to their computers' (p. 197), but recreational computer use is related to increase in academic achievement (Rocheleau, 1995). Public concern surrounds children's exposure to pornography and sexual predators via the Internet (Subcommittee on Telecommunications and the Internet, 2001), but schools have a mandate to enhance Internet access for children of all ages (Tarpley, 2001). Such conflicting research findings and visible discrepancies between research and practice may be the result of insufficient theoretical frameworks for understanding the effects of media on children's development (Boehnke et al, 2002).

Kirkorian et al (2008) stated that interactive media can also become a factor in the decline of educational results of the participant. Anderson (2001), emphasized that for the success of a web based course one has to consider the factors of both the recipient and mechanism or technology used and how students will deal with the new source or medium and what is output of the course for a successful retention of the experience by the learner.

With a population of around 208 million, Pakistan is the world's sixth most populous country with around $39 \%$ of population comprising children, while $12 \%$ in the $0-4$ year age bracket (early childhood) and $21 \%$ between the ages of 10 and 19 (adolescents) (Pakistan, 2017). While the proportion of children and adolescents in the total population is expected to decline to $41 \%$ by 2022 , their absolute number is projected to rise by 3.347 million, an increase of $4 \%$ (Planning and Development Department Projections 2010-30, 2010). These figures may imply a potential demographic dividend, but will also pose serious challenges in terms how adolescents are affected by different mainstream media in their moral, social and cognitive growth has emerged as structured phenomena in last decade around the world and especially in Pakistan (UNICEF, 2017). Cognitive and academic development of a child is heavily connected to the exposure to interactive social media (Wartella and Anderson 2008). Adolescents aging 8 to 16 years has a cognitive strengthen in terms of keeping things in mind and critically thinking about things and also 
solving problems by using logical reasoning. These developments can only be measured by the child's social behavior of developing relationships without the help of any adult or under control of any parent or parental network. Youngsters are more inclined towards relationships with the other children of their age and sex and also get a desire of being liked and accepted by their peer group. There is a strong connection between time spent on internet and their effect on adolescents.

Shrum (1995) states that heavy and light user of media cannot have same effects and experiences. The concept of media socialization, which examines specifically how different kinds of media influence children's cognitive and social growth, is a perspective which has emerged over the last fifteen years as a key framework for understanding how and what children take from their experiences with communication.

In modern age of technology youth rely heavily on internet, cable and movies and consider these sources as authentic source of entertainment and information. The increasing popularity and utilization of media is raising many questions that what effects it has on the social, moral and cognitive development of adolescents and children. Is social media really successful in cultivating new things and phenomena among adolescents?

\section{The Concept of Social Media}

All the digital media with the option of real time respond and feedback from the users can be categorized as interactive media and it include Whatsapp, Facebook, Twitter and Instagram. To understand the cognitive, social and moral effects of social media on users, it is really important to identify which form of media is categorized as social media by the researcher. Researcher rely on the definition of Borgatti and Foster (2003, p.993), according to them when more than two actors are connected in a way that they can interact and respond to each other. Researcher has identified the facebook as social media platform and researcher has identified its actors as those who are in their adolescent and are connected to each other through a peer group and friendship nexus.

To explain the social network of people and the interaction process, Kaplan and Haelein (2010) elaborated that social media comprises of web-based and mobile technologies used to change communication into interactive dialogue. These are the set of internet-based applications that consist of ideological and technological basis of web and that permit the creation and exchange of user-generated content. Social media are technologies that facilitate social interaction, collaboration, and enable deliberations across stakeholders (Bryer and Zavattaro, 2011, p.327; Chien and Bryer, 2012, p.88).

Waleed M. and Mohd S. (2012) explained that social networking exist so as to facilitate communication among diversified people regardless of the distance and allow them to share information, files and pictures and videos, create blogs and send messages, and conduct real-time conversations. There is no doubt that social medium such as Facebook has a great ability to instantaneously spread messages to the masses, unrestricted by time and space (Harlow, 2012).

Social Network Sites, Facebook in particular has proved to be a tool for social activism and a potent instrument for sparkling, stirring and setting in active social movements in the recent times (Alabi, 2013). That's why the researcher has selected it for the present study. In year 2003 Facebook and orkut entirely altered the concept of social networks in the history of social media. After year 2003, social networks were very much advance with new features, by using new features the user can change the whole appearance of the website on his profile which is a step towards evolution.

\section{Statement of the problem /Rationale}

The most used social media website that people of Pakistan are using is Facebook as 92.06\% of our population which has access to internet is actively using Facebook (pakistan-social-media-stats-2018, 2018) . Since Pakistani children are massively getting exposed to social networking sites there is grave 
need for assessing the impact of increased technology usage for cognitive, social and moral development of adolescents. Secondly this research will test cultivation effects approach for Social media because the researcher finds no significant amount of work done in the regard of cultivation effect for social media.

This research has been conducted with a goal of identifying the problems and the prospects that comes due to the usage of social networking technology in cognitive, social and moral development. It is expected from the youth that they will learn social patterns and norms that are conveyed through social media entertainment and leisure stuff. It is considered that students will seek formal education in their educational institutes. Students draw apprehensions and perception about the social world as it is being projected through media. In these modern times, one must know that media helps in shaping and reinforcing our traditions and beliefs, these beliefs ultimately lead us to certain decisions regarding right or wrong and reality and fiction. Knowing the power of social media, the researcher tries to understand the working of social media and how does it affect youth personality development. In present study an attempt is made to gage out the impact of this informal educational content on adolescents of Pakistan. Norms, culture and beliefs in any society are shaped and changed during interaction with others. Social media is the largest source of interaction and informal education. Individuals seek information from interactive social media. They share their own beliefs and sometime as a result of cultural imperialism alter their moralities.

Cultivation theory was designed to understand and measure the effect of television on the audience but with the technology advancement now social media is becoming the most powerful tool of modern time and has gain tremendous amount of popularity in a short period of time as compared to old media tools e.g. newspaper, TV and radio etc. Researcher wants to verify the significance of this theory on new social media domain as it has on traditional media platforms in regard of injecting newer concepts and ideas into users. Cultivation theory heavily rely on the phenomena of heavy and light users of media i.e. how much a user is exposed to media and also time spent by a teenager would also be considered by the researcher to check how powerful the impact is on users. It is assumed that greater the amount of time spend on social media would result in more proximity in thoughts regarding social phenomena which are propagated in social world.

\section{Objectives}

The study aims to understand and explore the effects of social networking sites i.e. Facebook and twitter on cognitive, social and moral skills development with the help of a survey conducted using purposive sampling mechanism of 1000 respondents in Pakistan. Study is conducted considering these objectives:

- To evaluate the effects of interactive social media on cognitive, moral and social development of adolescents.

- To investigate the cultivation effects approach in case of interactive social media.

- To analyze the gender wise differences among facebook users.

\section{Significance of Study}

Society functioning has been greatly affected by social media platforms in this millennium (Shapiro \& Margolin, 2014). Usage of social media has become a part and parcel of everyday's life and its has a greater impact on the developmental stages of a individual raging form infancy to becoming senior adult. The availability of social media platforms and information over these platforms transform social aptitude to think behave and feel towards social issues and other individuals (Boyd, 2007; Buffardi \& Cambell, 2008). The researcher aims to study the influential role of social media usage on adolescents in their cognitive, moral and social development. The secondary experiences of the researcher will enlighten the people about how young people are attached to these social media worlds and how these SMTs influence the cognitive, social and moral development of adolescents. Youngsters cannot escape media due to its heavy exposure at home and school. Due to social media expansion youth is spending a major portion of 
their time on their computers and internet. According to the findings of "Social media and technology use" by Pew Research center (2015), facebook is the most popular social media platform and almost $71 \%$ of youngsters of ages 13 to 17 use facebook. According to Roberts and Foehr (2008) adolescents are more engaged in media activities than any other indoors or out door activity. According to Kaiser Family foundation study of 2010 mobile phone is the last thing touched by a teenager before falling asleep and first thing they'll reach for after waking. With the advancement in the technology number of problematic behaviors of teens has also increased. (Runions et al. 2007).

\section{Justifications and Likely Benefits}

Pakistan has achieved a rapid growth in technological advancement in past few decades. Interactive media usage has almost become a compulsion in the education and schooling structure. Interactive social media and smart phones apps are getting serious response from adolescents. It is the most sensitive age time of any individual. Adolescences hold a key role in the shaping of individual's beliefs and personality development.

This study will help technology creators, school ownerships and parents to gage the impacts of technology on cognitive, social, moral and personality development. It will help Pakistani educational administration to bring about great changes in their setups according to the insight from findings of the current study. It will also add to the theoretical body of knowledge. This study will examine the cultivation role of interactive social media which has been previously checked in case of television only.

\section{Hypotheses}

On the basis of literature reviewed by researcher for the present study the researcher has developed following hypothesis:

H1: Greater the usage of interactive social media, greater would be the cultivation effects.

$H_{1}{ }^{\prime}$ : Usage of interactive social media has impact on cognitive development of adolescents.

$\mathrm{H}_{2}{ }^{\prime}$ : Usage of interactive social media has impact on social development of adolescents.

$\mathrm{H}_{3}{ }^{\prime}$ : Usage of interactive social media has impact on moral development of adolescents.

H2: Significant differences in cognitive, social and moral development are likely to be observed among male and female adolescent users of interactive media.

\section{Application of Cultivation Hypothesis on Social Media in Present Research:}

This study focuses on how the social construction of a reality occurs on social media networking sites that reinterpret Gerbner's cultivation theory in an evolved platform.More and more individuals are shifting to digital media from traditional media(Williams, 2006). Considering such, the present study is testing the cultivating ability of social media, a newer non-traditional media, and specifically the cultivated effects of social media onadolescent's development. The research has applied this theory because cultivation hypothesis caters to all the segments of society. This study will try to gage how social media can bring changed in adolescent development through reported exposure to social media usage. The main hypothesis of the present study is greater the exposure to social media greater the impact on adolescents' development. The cultivation theory also states that as the media exposure increases, people perceive the information floated through media as real world. Social Media starts cultivating things among adolescents and transforms their cognitive, social and moral behavior and development. In present study the researcher has categorized the facebook users into two main categories and following sub categories depending upon their usage of social media. Consumers are those who only consume social media content, they rarely post updates; rather they are the passive users. Whereas, producers are those who are active users of Social media. They consume and produce the social media content. They are much more vulnerable to the effects of social media. The researcher has categorized the facebook consumers and producers into following categories depending upon their media usage and activities. . 


\section{Application of Social Learning theory}

In the light of all these theories stated above, it is important to mention that the researcher has formulated an amalgam of the two theories in order to assess the kind of effects that are taking place in the lives of the sample under study. Are these effects long-lasting or short term Hence, the researcher intended to explore all this for which the base of above mentioned theories was most suitable and required.

\section{Research design}

Keeping in view the nature of present study the researcher has selected following methodsthat suits best for the completion of data gathering task for this research.

\section{a. Survey \\ b. Focus Group}

\section{Research Method 11.1 Survey}

In this study, survey method has been used to gather the data that is quantitative in nature from large representative but diverse and widely scattered population. The survey has aided the researcher in collecting information directly from the facebook users. (heavy, moderate and light viewers) so that a proper analysis could be made by comparing the differences in their cognitive, social and moral skills development. The changes in their development have been hence figured out through the information provided on a quantitative scale. This research was conducted during February 2018 to September 2018. The data was collected in 2018.

\subsection{Population}

Due to the time and budgetary limitations, the total area covered by the study was only five capitals (four province capital and one country capital) of Pakistan i.e. Lahore, Karachi, Islamabad, Peshawar and Quetta only. Wimmer and Dominick (1993) define population as "A group or a class of subjects, variables, concepts or phenomena." In the light of the above definition, total population of this study comprises all adolescent social media i.e. facebook users aged 11 to 19 years and residing in Pakistan. The researcher selected this age group for the study because it is the most vibrant, active and innocent part of their lives. It was not feasible for the researcher to approach the total population therefore sampling technique was applied.

\subsection{Sampling Method}

Even a modest sized survey typically requires considerable time, material, money and assistance. Thus the researcher has applied purposive sampling technique to collect the data considering the definition of Wimmer and Dominick (1993) "a sample is the subset of the population that is taken to be the representative of the entire population". The researcher has selected purposive sampling technique because only adolescents' facebook users were required for this research. The researcher has selected a sample of 530 adolescents, 106 from each capital. The target facebook users were selected from schools and colleges having almost same patterns and fee structures.

\subsection{Operationalization of User Categories}

The researcher has then categorized the users as Consumers (passive users) and producers (active users). The researcher has devised the following four categories to check the cultivation impact on adolescents' skills.

1. Passive users

2. Slightly Active Users

3. Moderately Active Users

4. Highly Active users 
Passive users and slightly active users fall in the category of Light users. Moderately Active and Highly Active users fall in the category of Heavy users. The researcher has devised the above discussed four categories of Social Media on the basis of following parameters. The researcher has selected the belowmentioned factors based on the conclusion drawn after reviewing the relevant literature

\section{Passive users}

a. Does not participate on facebook forum.

b. Access pages infrequently.

2. Slightly active users

a. Rarely post self status.

b. Consumes content on daily basis.

c. Sign in daily

3. Moderately Active

a. Actively share facebook feed.

b. Sign in multiple times a day.

c. Produce content on daily basis.

\section{Highly Active users}

a. Heavy daily usage and creation of content.

b. Sharing personal views and updates multiple times a day.

c. Sharing and tagging.

d. Popularity contest: high number of fans and followers.

e. Be the first to share latest stuff and news online.

f. Constantly check feeds and timelines after posting.

\subsection{Variables of the Study}

The study has independent and dependent variables:

\subsubsection{Independent Variable}

"Social media usage" was an independent variable of the study. It means the facebook login frequency and the time spent on facebook in different activities by the respondent. Therefore greater the time spent using facebook greater will be the usage.

\subsubsection{Dependant Variables}

- Cognitive skills

- Moral skills

- Social Skills

- Cultivation effect

\section{Conceptualization}

The major terms used in the study are defined below:

\section{1) Social Media}

\section{a. Formal}

Generally speaking Social media is a computer based technology that facilitates the sharing of ideas and information and the building of virtual networks and communities. It offers easy electronic communication of personal information and other content such as videos and photos etc.

\section{b. Operational}

Among youngsters facebook is the most widely used social networking site to maintain social networks. That's why in present research the researcher has selected facebook. In present study social media refers to of facebook only. 


\section{2) Cognitive Skills}

a. Formal

Cognition is a general term encompassing mental processes such as attention, perception, comprehension, memory and problem solving (Solso et al, 2005). Cognitive development refers to changes in cognition over time.

\section{b. Operational}

In present research the researcher has included following items based on previous literature and societal justification to measure cognitive development of adolescents'.

- Better understanding of events/phenomena/things

- Improvement in verbal communication

- Increase in knowledge about world

- Improvement in writing skills

- $\quad$ Good and strong decision making power

- Ability to analyze the problems and situations

- Ability to solve the problems

- Improved ability to recognize things

- $\quad$ He is learning new trends

- $\quad$ Enhancing creativity

- $\quad$ Ability for logical reasoning

\section{3) Social Skills}

\section{i. $\quad$ Formal}

Generally speaking social skill is any competence facilitating interaction and communication with others where social rules and relations are created, communicated and changed in verbal and non verbal ways.

\section{ii. Operational}

In present research the researcher has selected the following factors as a measure of social skills among adolescents.

- Communication with family and friends

- Time spent in overall offline activities. ( Reading newspaper, watching TV, Offline social activities etc)

- Online social circle

- Needs gratification

- Maintaining of online social capital.

\section{4) Moral Skills}

\section{i. Formal}

Moral development focuses on emergence, change and understanding of morality from infancy through adulthood, Morality develops across a lifetime and is influenced by an individual's experiences, and surroundings when faced with moral issues through different periods' physical and cognitive 
development.

\section{ii. Operational}

For the present study the researcher has gagged the moral development of adolescents with the help of following factors keeping in view the societal justification of moral values.

- Able to differentiate between right and wrong.

- Courage to give positive feedback

- Accept the consequences

- Ability to say truth on all platforms

- Forgiveness

- Caring about others

- To keep promises and words

- Know and follow my beliefs and values.

- Honesty

\section{5) Cultivation}

\section{i. Formal}

Generally speaking cultivation is a process of trying to aquire or develop a quality or skill.

\section{ii. Operational}

For present study the term cultivation refers to the adoption of the theory of Cultivation. In case of traditional and social media cultivation theory states that media cultivates vales, beliefs and skills among viewers and users who consume media more frequently than others.

\section{Data Collection}

\subsection{Tool of Data Collection.}

In this research, a questionnaire was selected as a tool for data collection. The closed ended questionnaire for survey consisted of 4 parts as it has four variables. The tool to measure the facebook usage, social skills and cognitive skills was designed by the researcher according to the needs of this study. The tool to measure moral skills was adopted and used with the permission of author. A self designed open ended questionnaire was used to obtain the opinion of participants of focus group. The language of questionnaire for both survey and focus group was English and Urdu.

\subsection{Pre Testing and Reliability of Test}

The survey questionnaire was pre-tested on 50 individuals. The result revealed certain shortcomings in the instrument so the researcher made modifications before finalizing it. To test the reliability of the instrument, Cronbach's alpha approach was applied. This method of testing the reliability is commonly used when study of knowledge, attitude and practice is conducted and questions are in the form of Likert's scale (Likert's-1952). In a Likert's scale a person expresses an opinion by rating his agreement with a series of statements (Hanif, \& Ahmad, 2004).

\subsection{Data Processing}

Each of dependent variables was operationalized into a set of parameters and the answers were obtained on Likert 5 - point scale as mentioned in table 1. 


\section{Table 1}

\section{Opinion and Respective Values}

\begin{tabular}{|l|l|}
\hline Opinion Value & Value \\
\hline Strongly Agree & 5 \\
\hline Agree & 4 \\
\hline Neutral & 3 \\
\hline Disagree & 2 \\
\hline Strongly Disagree & 1 \\
\hline
\end{tabular}

The users are categorized on the basis of their level of facebook usage. There usage is categorized into three vales i.e heavy users, moderate users and light users as mentioned in table 2.

Table 2

Level of Social Media Usage

\begin{tabular}{|l|l|l|l|}
\hline $\begin{array}{l}\text { Level of Social Media } \\
\text { Usage }\end{array}$ & Score & Category & Effect Type \\
\hline Once a month & 1 & Light users & No to low Effect \\
\hline Several times a month & 2 & Light users & No to low Effect \\
\hline Once a week & 3 & Light users & No to low Effect \\
\hline Several times a week & 4 & Moderate Users & Medium Effect \\
\hline Once a day & 5 & Moderate Users & Medium Effect \\
\hline Several times a day & 6 & Moderate Users & Medium Effect \\
\hline Once an hour & 7 & Heavy Users & High Effect \\
\hline Several times an hour & 8 & Heavy Users & High Effect \\
\hline All the time & 9 & Heavy Users & High Effect \\
\hline
\end{tabular}

\subsection{Demographic Characteristics of Respondents}

\section{Table 3}

Demographic Characteristics of the Respondents

\begin{tabular}{|c|c|c|c|c|}
\hline $\begin{array}{l}\text { S. } \\
\text { No. }\end{array}$ & $\begin{array}{l}\text { Demographic } \\
\text { characteristics }\end{array}$ & $\begin{array}{l}\text { Description of } \\
\text { Characteristics }\end{array}$ & $\mathbf{f}$ & $\%$ \\
\hline \multirow[t]{2}{*}{1.} & \multirow[t]{2}{*}{ Gender } & Male & 262 & 49.4 \\
\hline & & Female & 268 & 50.6 \\
\hline & Total & & 530 & 100.0 \\
\hline \multirow[t]{2}{*}{2.} & \multirow[t]{2}{*}{$\begin{array}{l}\text { Age } \\
\text { (years) }\end{array}$} & $\begin{array}{l}\text { Early adolescents } \\
\text { (10-14 years) }\end{array}$ & 264 & 49.8 \\
\hline & & Late adolescents & 266 & 50.1 \\
\hline
\end{tabular}




\begin{tabular}{|l|l|l|l|l|}
\hline & & (15-19 years) & & \\
\cline { 2 - 5 } & Total & & $\mathbf{5 3 0}$ & $\mathbf{1 0 0 . 0}$ \\
\hline \multirow{3}{*}{$\begin{array}{l}\text { Facebook } \\
\text { Login } \\
\text { frequency(per } \\
\text { Day) }\end{array}$} & $\begin{array}{l}\text { Light users } \\
\text { (Less than 5 times a } \\
\text { day) }\end{array}$ & $\begin{array}{l}182 \\
\text { Moderate Users } \\
\text { (6 to 12 times per day) }\end{array}$ & 174 & 34.33 \\
\cline { 3 - 5 } & $\begin{array}{l}\text { Heavy Users } \\
\text { (13 to 19 times or } \\
\text { more) }\end{array}$ & 174 & 32.83 \\
\hline & Total & & $\mathbf{5 3 0}$ & 32.83 \\
\hline
\end{tabular}

\subsection{Hypothesis Testing}

\section{Table 4}

Regression Analysis of Social Media (Facebook) Usage and its Impact on Moral Skills

\begin{tabular}{|l|l|l|l|l|l|l|l|l|}
\hline & $\begin{array}{l}\text { Unstandardized } \\
\text { Co-efficient }\end{array}$ & $\begin{array}{l}\text { Standardized } \\
\text { Co-efficient }\end{array}$ & & & & & & \\
\hline Model & \multicolumn{1}{|c|}{$B$} & $\begin{array}{l}\text { Std. Error } \\
B\end{array}$ & $B$ & $T$ & $p$ & $d f$ & $F$ & $R^{2}$ \\
\hline Constant & $\begin{array}{l}53.732 \\
.080\end{array}$ & $\begin{array}{l}1.385 \\
.009\end{array}$ & .349 & 8.546 & .000 & 528 & 73.042 & .122 \\
$\begin{array}{l}\text { Facebook } \\
\text { Usage }\end{array}$ & & & & & & & & \\
\hline
\end{tabular}

\section{Dependent Variable Moral Skills}

A linear regression analysis was conducted in order to find the effect of face book usage on students' moral skills in Pakistan. As table 4 shows that use of face book was found to be significant with $\left(R^{2}=.122\right)$ at $p \leq 0.05$ level of significance. The findings of the effect of face book usage on students' moral skills was significantly predict the dependent variable with $(\beta=.349, \mathrm{~F}=.419, \mathrm{p}=0.000)$. The findings of these variables show that use of face book has influence on the moral skill development of students in Pakistan but the results also indicate that relationship among facebook usage and moral skills development is weaker. It means that that in society there are many other factor that contribute in moral skills development of adolescents in addition to social media.

\section{Table 5}

Regression analysis of social media (facebook) usage and its impact on social skills

\begin{tabular}{|c|c|c|c|c|c|c|c|c|}
\hline & $\begin{array}{l}\text { Unstandardized } \\
\text { Co-efficient }\end{array}$ & $\begin{array}{l}\text { Standardized } \\
\text { Co-efficient }\end{array}$ & & & & & & \\
\hline Model & $B$ & $\begin{array}{l}\text { Std. Error } \\
B\end{array}$ & $B$ & $T$ & $p$ & $d f$ & $F$ & $R^{2}$ \\
\hline $\begin{array}{l}\text { Constant } \\
\text { Facebook } \\
\text { Usage }\end{array}$ & $\begin{array}{l}80.949 \\
.053\end{array}$ & $\begin{array}{l}1.807 \\
.012\end{array}$ & 0.188 & 4.387 & .000 & 528 & 19.246 & .033 \\
\hline
\end{tabular}




\section{Dependent Variable Social Skills}

A linear regression analysis was conducted in order to find the significance effect of face book usage on students' social skills in Pakistan. As table 5 shows that use of face book was found to be significant with $\left(\mathrm{R}^{2}=.033\right)$ at $\mathrm{p} \leq 0.05$ level of significance. The findings of the effect of face book usage on students' social skills was significantly predict the dependent variable with $(\beta=.188, \mathrm{~F}=19.246, \mathrm{p}=0.000)$. The findings of these variables show that use of face book has a very weaker influence on the social skill development of students in Pakistan.

\section{Table 6}

Regression analysis of social media (facebook) usage and its impact on cognitive skills

\begin{tabular}{|c|c|c|c|c|c|c|c|c|}
\hline & $\begin{array}{l}\text { Unstandardized } \\
\text { Co-fficient }\end{array}$ & $\begin{array}{l}\text { Standardized } \\
\text { Co-efficient }\end{array}$ & & & & & & \\
\hline Model & $B$ & $\begin{array}{l}\text { Std. Error } \\
B\end{array}$ & $B$ & $T$ & $p$ & $\overline{d f}$ & $F$ & $R^{2}$ \\
\hline $\begin{array}{l}\text { Constant } \\
\text { Facebook } \\
\text { Usage }\end{array}$ & $\begin{array}{l}28.997 \\
.082\end{array}$ & $\begin{array}{l}1.047 \\
.007\end{array}$ & .452 & 11.653 & .000 & 528 & 135.785 & .205 \\
\hline
\end{tabular}

\section{Dependent Variable Cognitive Skills}

A linear regression analysis was conducted in order to find the significance effect of face book usage on students' cognitive skills in Pakistan. As table 6 shows that use of face book was found to be significant with $\left(\mathrm{R}^{2}=.205\right)$ at $\mathrm{p} \leq 0.05$ level of significance. The findings of the effect of face book usage on students' cognitive skills was significantly predict the dependent variable with $(\beta=.452, \mathrm{~F}=135.785, \mathrm{p}=0.000)$. The findings of these variables show that use of face book influence on the cognitive skill development of students in Pakistan.

\section{Gender wise T-test Scores}

\section{Table 7}

\section{Gender wise comparison of social media consumption reasons}

\begin{tabular}{|l|l|l|c|c|c|l|l|}
\hline Measures & Gender & $N$ & \multicolumn{1}{|l|}{$M$} & SD & t-value & Df & Sig. \\
\hline & & & & & & & \\
\hline Education & Male & 262 & 37.53 & 13.14 & 1.269 & 528 & .975 \\
Purpose & Female & 268 & 36.05 & 13.52 & & & \\
\hline Media & Male & 262 & 54.13 & 19.82 & 2.730 & 528 & .703 \\
Sharing & Female & 268 & 49.50 & 19.21 & & & \\
\hline
\end{tabular}

An independent sample t-test was applied to find out the media consumption purposes differences among male and female adolescents in Pakistan. It was showed from the above table that there was no significance mean difference existed at $p \leq 0.05$ level of significance in Pakistan. It is concluded that male and female students have no differences of opinions regarding face book usages i.e. face book usage for educational purposes and media sharing in Pakistan. 


\section{Table 8}

Gender wise comparison in consumption of Face Book

\begin{tabular}{|l|l|l|l|l|l|l|l|}
\hline Measures & Gender & $N$ & $M$ & $S D$ & $t$-value & $D f$ & Sig. \\
\hline $\begin{array}{l}\text { Face Book } \\
\text { Usage }\end{array}$ & Male & 262 & 146.35 & 43.97 & 2.36 & 528 & .173 \\
\hline
\end{tabular}

An independent sample t-test was applied to find out the difference in facebook usage among male and female adolescents in Pakistan. It was showed from the above table that there was no significance mean difference existed at $\mathrm{p} \leq 0.05$ level of significance in Pakistan. It is concluded that male and female students have no differences of opinions regarding face book usages in adolescents in Pakistan.

Table 9

Gender wise Comparison of Social Media (Face Book) effects on social skills

\begin{tabular}{llllllll} 
Measures & Gender & $\boldsymbol{N}$ & $\boldsymbol{M}$ & $\boldsymbol{S} \boldsymbol{D}$ & $\boldsymbol{t}$-value & $\boldsymbol{D f}$ & Sig. \\
& & & & & & & \\
\hline Amount of & Male & 262 & 19.54 & 5.93 & .075 & 528 & .576 \\
Time & Female & 268 & 19.50 & 5.76 & & & \\
Impact on Life & Male & 262 & 15.94 & 3.54 & 1.87 & 528 & .548 \\
& Female & 268 & 15.36 & 3.48 & & & \\
Gratify Needs & Male & 262 & 19.01 & 4.30 & .489 & 528 & .433 \\
& Female & 268 & 18.83 & 3.96 & & & \\
Interpersonal & Male & 262 & 7.61 & 1.64 & .604 & 528 & .193 \\
Communication & Female & 268 & 7.52 & 1.72 & & & \\
Online Social & Male & 262 & 11.33 & 2.51 & 3.028 & 528 & .630 \\
Capital & Female & 268 & 10.67 & 2.50 & & & \\
Real World & Male & 262 & 13.69 & 3.23 & .166 & 528 & .042 \\
Relationship & Female & 268 & 13.64 & 3.55 & & & \\
\hline
\end{tabular}

An independent sample t-test was applied to draw gender wise comparison of social media (face book) effects on adolescents in Pakistan in terms of their social skills on the basis of their sub scales. It was showed from the above table that there was significance mean difference existed in SNS usage and its impact on real world relationship as compared to the other factors (amount of time spent on SNS, impact on life, and needs gratification, interpersonal communication and online social capital) at $\mathrm{p} \leq 0.05$ level of significance in Pakistan. It is concluded that male and female students have differences of opinions in SNS usage and its impact on real world relationship i.e. loss of privacy, less emotional bonding, emotional disturbance, more reliance on electronic medium and loss of time etc) on adolescents in Pakistan in terms of their social skills.

Table 10

Gender wise effect of Social Media (Face Book) on social development

\begin{tabular}{|l|l|l|l|l|l|l|l|}
\hline Measures & Gender & $N$ & $M$ & $S D$ & t-value & Df & Sig. \\
\hline Social Skills & Male & 262 & 89.19 & 13.13 & 1.219 & 528 & .991 \\
& Female & 268 & 87.83 & 12.51 & & & \\
\hline
\end{tabular}

An independent sample t-test was applied to find out the differences of male and female students' 
perception regarding the effects of social media i.e. face book usages of adolescents in Pakistan in terms of their social skills. it was showed from the above table that there was no significance mean difference existed at $p \leq 0.05$ level of significance in Pakistan. it is concluded that male and female students have no differences of opinions regarding face book usage in adolescents in Pakistan in terms of their social skills.

\section{Table 11}

\section{Gender wise effect of Social Media (Face Book) on cognitive development}

\begin{tabular}{|l|l|l|l|l|l|l|l|}
\hline Measures & Gender & $N$ & $M$ & $S D$ & $t$-value & $D f$ & Sig. \\
\hline Cognitive & Male & 262 & 41.61 & 8.06 & 2.774 & 528 & .404 \\
Skills & Female & 268 & 39.65 & 8.20 & & & \\
\hline
\end{tabular}

An independent sample t-test was applied to find out the differences of male and female students' perception regarding the effects of social media i.e. face book usages of adolescents in Pakistan in terms of their cognitive skills. it was showed from the above table that there was no significance mean difference existed at $\mathrm{p} \leq 0.05$ level of significance in Pakistan. It is concluded that male and female students have no differences of opinions regarding face book usage in adolescents in Pakistan in terms of their cognitive skills.

\section{Discussion on Inferential Statistics Results}

Inferential statistics were applied to generalize and predict the factors of social, moral and cognitive skills development and cultivation effects of facebook on adolescent of Pakistan. For this purpose linear regression analysis were run to find out the impact of facebook on social, moral and cognitive skills, whereas, the results exposed that significant value $\mathrm{p} \leq 0.05$ with $\left(\mathrm{R}^{2}=.122\right)$. The effect of facebook usage on students' moral skills was significantly predict the dependent variable with $(\beta=.349, F=.419$, $\mathrm{p}=0.000$ ). The findings of these variables show that use of face book influence on the moral skill development of students in Pakistan. The results revealed that youth of the country would expose to sexiting through personal, picture, live chat and videos, texting, pornography as well as behavioral problems. Bremer \& Rauch, (1998) said that most of teenagers are using social media for unethical interaction all over the world.

The findings also disclosed the effect of facebook usage on students' social skills in Pakistan, whereas a linear $\mathrm{R}$ analysis was applied. The use of facebook was found with significant value $\mathrm{p} \leq 0.05$ with $\left(\mathrm{R}^{2}=\right.$ $.033)$ which is predict the dependent variable with $(\beta=.188, F=19.246, p=0.000)$ that the effect of facebook usage on students' social skills. It showed the use of face book influence on the social skill development of students in Pakistan. It is a matter of discussion that facebook is effecting the social lives of the teenagers of the country. Through facebook they could communicate with each other, to learn new things, to ask for other's help, to meet up their needs effectively in an appropriate way, make new friends, develop a healthy and pleasant relationship with others. These processes needed for obtaining social skill set are dependent of various tasks and factors e.g. through education, social interaction, communication with peer and engaging in face to face activities. Tom P. Dowd, Jeff Tierney (2005) said that youth is most influential factor for the development of the society where they are using social media for communication among their social spam.

The linear regression analysis revealed that facebook has a significance effect on students' cognitive skills in Pakistan. The results illustrated that there is a significant relationship $\mathrm{p} \leq 0.05$ between facebook and cognitive skills with the predicted dependent variable with $(\beta=.452, \mathrm{~F}=135.785, \mathrm{p}=0.000)$. This demonstrated that facebook could increase the abilities to remember things, imagination, ability to solve problems, critical thinking and examining things and ways of logical reasoning as Khalid (2017) predicted. 
The sample t-test results explored that male and female students have no differences of opinions regarding facebook usages for educational purposes and media sharing in Pakistan with the significant level of $\mathrm{p} \leq 0.05$. It revealed that both are using facebook frequently

T-test was adopted to find out the gender difference regarding facebook usage and its effects on social skills of adolescents'. It is observed from results that female and male youth have difference of opinions regarding consumption of SNSs in terms of factors i.e. (amount of time spent of facebook, impact on life, need gratification, interpersonal communication, online social capital and real-world relationship) in adolescents in Pakistan in terms of their social skills.

The ANOVA explored that facebook usage frequency has no effect on moral skills of adolescents in Pakistan. Whereas the Post-hoc (HSD) test unveiled that facebook usage frequency has significant impact on cognitive skills of adolescents in Pakistan.

\section{Limitations}

- Every study has some limitations which basically didn't incorporate in the research, it may be conceptual, operational, theoretical, methodological, technical, population and area wise.

- The current study was limited to only three concepts including cognitive, social and moral, while didn't include economical, educational, political etc perspective in research. The other researchers needed to do research on the other factors that to present solution of the problems.

- Methodological limitation was also there because a single technique of each methodology was applied for the diagnosing of the issue, whereas, if the researcher uses other methods and techniques, it would be better to understand the problem and would be easy to present solution.

- The research was also limited to a particular area, whereas the problem in the over the world and country, so researchers also require to ensure nationwide research on the said topic.

- The research was also restricted to only adolescents, but research also entail on children, women and others as well.

\section{Recommendations}

- It is recommended to the researcher that to do research on the other factors of the issue.

- It is also suggested to the researcher that to expand the study nationwide.

- It is also recommended to the researcher to include people of every walk of life in the research.

- It is recommended to the youth that use social media for positive change instead of negative.

- It is suggested to adolescents to use social media for educational and informative purposes in its place of video and movies.

- It is also recommended to youth to use facebook and other social site for getting knowledge.

- It is also suggested to the students to improve socialization instead of violation.

- It is also recommended to the adolescents to use facebook encircle of morality.

- It is also suggested to students to use Facebook for exploring for their creativity and encouragement.

- It is also suggested to students to enhance research skills, writing skills and improve vocabulary through facebook.

- It also recommended to youth to improve your social, cognitive and moral skills through social media usage.

- It is suggested to the parents to control their youth from abuses of social media.

- It is also recommended to them to regulate them while using Facebook and other social sites.

- It is also suggested to them to sustain social media education in educational institutions.

- It is recommended to the government to implement cyber law in the country to overcome the social media misuse in the country.

- It is also suggested to the government to regularize social media for ethnic conflict solution. 


\section{References}

Anderson, L. W., \& Krathwohl, D. R. (2001). A Taxonomy for Learning, Teaching and Assessing: A Revision of Bloom's Taxonomy of Educational Objectives: Complete Edition. New York: Longman

Alabi, O. F. (2013). A survey of Facebook addiction level among selected Nigerian University undergraduates. New Media and Mass Communication, 10(2012), 70-80.

Bryer, T. A., \& Zavattaro, S. M. (2011). Social media and public administration: Theoretical dimensions and introduction to the symposium. Administrative Theory \& Praxis, 33(3), 325-340.

Borgatti, S., and Foster, P. C. (2003) 'The Network Paradigm in Organizational Research: A Review and Typology', Journal of Management, 29:6, 991-1013

Boyd, Danah M., and Nicole B. Ellison, "Social network sites: Definition, history, and scholarship", Journal of Computer-Mediated Communication 13, 1 (2007): 516-529.

Buffardi, L. E., \& Campbell, W. K. (2008). Narcissism and social networking web sites.

Personality and social psychology bulletin, 34(10), 1303-1314

Boehnke, K., Munch, T. \& Hoffmann, D. (2002) Development through Media Use? A German Study on the Use of Radio in Adolescence, International Journal of Behavioral

Development, 26, pp. 193-201. http://dx.doi.org/10.1080/01650250042000735

Bushman, B.J. \& Huesmann, L.R. (2001) Effects of Television Violence on

D.G. Singer \& J.L. Singer (Eds) Handbook of Children and

Aggression,

the Media, pp. 255-

298. Thousand Oaks: Sage.

Bushman, B.J. \& Huesmann, L.R. (2001) Effects of Television Violence on Aggression,

D.G. Singer \& J.L. Singer (Eds) Handbook of Children and the Media, pp. 255- 298.

Thousand Oaks: Sage.

Foster, K. C., Erickson, G. C., Foster, D. F., \& Brinkman, D. (1994). Computer

administered instruction in phonological awareness: Evaluation of the DaisyQuest program. Journal of Research \& Development in Education.

Funk, J.B. \& Buchman, D.D. (1996) Playing Violent Video and Computer Games and Adolescent Selfconcept, Journal of Communication, 46, pp. 19-32. http://dx.doi.org/10.1111/j.1460-2466.1996.tb01472.x

Harlow, S. (2012). Social media and social movements: Facebook and an online Guatemalan justice movement that moved offline. New Media \& Society, 14(2), 225- 243.

Healy, J.M. (1998) Failure to Connect: how computers affect our children's minds - for better or for worse. New York: Simon \& Schuster

Ito, M., Horst, H., Bittanti, M., Boyd, D., Herr-Stephenson, B., Lange, et al. (2008). Living and learning with new media: Summary of findings from the digital youth project. Retrieved January 20, 2009, from: http://digitalyouth.ischool.berkeley.edu/report

Kirkorian, H. L., Wartella, E. A., \& Anderson, D. R. (2008). Media and young children's learning. The Future of Children, 18(1), 39-61.

Kaplan, A. M., \& Haenlein, M. (2010). Users of the world, unite! The challenges and opportunities of Social Media. Business horizons, 53(1), 59-68.

Pakistan, G. o. (2017). Census 2017. Islamabad: Government of Pakistan.

(2010). Planning and Development Department Projections 2010-30. Islamabad: National Institute of Population Studies

Roe, K. \& Muijs, D. (1998) Children and Computer Games: a profile of the heavy user, European Journal of Communication, 13, pp. 181-200.

Rocheleau, B. (1995) Computer Use by School-Age Children: trends, patterns and predictors, Journal of Educational Computing Research, 1, pp. 1-17. http://dx.doi.org/10.2190/MHUR-4FC9B187-T8H4

Shrum, L.J. (1995). "Assessing the social influence of television: A social cognitive

perspective on cultivation effects". Communication Research. 22 (4):

$402-429$. doi:10.1177/009365095022004002 
Tapscott, D. (1998). Growing up digital: The rise of the net generation. New York: McGraw Hill. Tarpley, T. (2001) Children, the Internet, and Other New Technologies, in D.G. Singer \& J.L. Singer (Eds) Handbook of Children and the Media, pp. 547-556. Thousand Oaks: Sage. Roberts, D. F., \& Foehr, U. G. (2008). Trends in media use. The future of children, 18(1), 11- 37. Runions, K. C., \& Keating, D. P. (2007). Young children's social information processing: Family antecedents and behavioral correlates. Developmental Psychology, 43(4), 838.

Rideout, V. J., Foehr, U. G., \& Roberts, D. F. (2010). Generation M 2: Media in the Lives of 8-to 18-Year-Olds. Henry J. Kaiser Family Foundation.

Rideout, V. J., Foehr, U. G., \& Roberts, D. F. (2016). Generation M2. Media $\quad$ in the lives of 8 to 18 year olds. A Kaiser Family Foundation Study; $\quad$ 2010. Menlo Park, Ca: Henry $\quad$ J Kaiser Family Foundation.

Shapiro, L. A. S., \& Margolin, G. (2014). Growing up wired: Social networking sites and adolescent psychosocial development. Clinical child and family psychology review, 17(1), 1-18.

UNICEF. (2017). Situationa Analysis of Children In Pakistan. Government of PAkistan. 
